\title{
EM BUSCA DE \\ FUNDAMENTOS PARA O \\ CONSTITUCIONALISMO \\ GLOBAL: ESBOÇO \\ DE TENDÊNCIAS \\ TEÓRICAS PARA A \\ CONSTITUCIONALIZAÇÃO \\ NO ÂMBITO DE UMA NOVA \\ ORDEM MUNDIAL ${ }^{1}$
}

IN SEARCH OF GROUNDS FOR GLOBAL CONSTITUTIONALISM: OUTLINE OF THEORETICAL TRENDS FOR THE CONSTITUTIONALIZATION WITHIN A NEW WORLD ORDER

ALLA RICERCA DEI FONDAMENTI PER IL COSTITUZIONALISMO GLOBALE: ABBOZZO

DI TENDENZE TEORICHE PER LA COSTITUZIONALIZZAZIONE NELL'AMBITO DI UN NUOVO ORDINE MONDIALE

1 Este artigo deriva de alguns dos aspectos abordados na tese de doutorado intitulada "O Constitucionalismo Global no Cenário de uma Nova Ordem Mundial: uma crítica a partir de uma teoria forte em face da realidade das relações internacionais contemporâneas", submetida pelo Prof. Maury Roberto Viviani ao Curso de Doutorado em Ciência Jurídica - CDCJ da Universidade do Vale do Itajaí - UNIVALI, no âmbito do convênio de dupla titulação com a Università degli Studi di Perugia - UNIPG (Itália). A tese teve a orientação do Prof. Dr. André Lipp Pinto Basto Luppi e a coorientação da Prof. Dra. Luciana Pesole. Parte da pesquisa doutoral foi desenvolvida na Universidade do Minho - UMINHO (Portugal), por intermédio de bolsa concedida pela CAPES, cujo estágio teve a supervisão do Prof. Dr. Mário João Ferreira Monte. 
André Lipp Basto Lupi²

Mário João Ferreira Monte 3

Maury Roberto Viviani ${ }^{4}$

Resumo: Este artigo tem por objetivo identificar tendências teóricas que possam servir de ponto de partida para a ampliação de reflexões sobre as possibilidades e os limites da constitucionalização em nível global/internacional, tendo em vista o cenário de intensificação da sociedade mundial.

Palavras chave: Constitucionalismo Global. Constitucionalização. Globalização. Soberania. Nova Ordem Mundial.

Abstract: This article aims to identify theoretical trends that can serve as a starting point for the expansion of reflections about the possibilities and limits of constitutionalization at the international/global level, in view the scenario of intensification of the global society.

Keywords: Global Constitutionalism. Constitutionalization. Globalization. Sovereignty. New World Order.

Riassunto: Questo articolo si propone di identificare tendenze teoriche che possano servire come punto di partenza per estendere le riflessioni sulle possibilità e i limiti della costituzionalizzazione a livello globale/internazionale, considerando lo scenario di intensificazione della società mondiale.

Parole chiave: Costituzionalismo Globale. Costituzionalizzazione. Globalizzazione. Sovranità. Nuovo Ordine Mondiale.

2 Doutor em Direito pela USP. Professor do Programa de Pós-Graduação Stricto Sensu em Ciência Jurídica - PPCJ da UNIVALI.

3 Doutor em Direito pela Universidade do Minho - UMINHO. Professor titular da Universidade do Minho - UMINHO (Portugal). Diretor do curso de Mestrado em Direito Judiciário e do Curso de Mediação Penal da Escola de Direito da Universidade do Minho.

4 Doutor em Ciência Jurídica pela UNIVALI/UNIPG. Professor e Coordenador da Escola do Ministério Público de Santa Catarina. Endereço eletrônico: mviviani@mp.sc.gov.br. 


\section{INTRODUÇÃO}

\section{7 publicação por Alfred Verdross, em 1926, da obra Die Verfassung der Völkerrechtsgemeinschaft ${ }^{5}$, a qual configurou um impulso temático 1 LinauguralparaumareflexãoarespeitodaconcepçãodoConstitucionalismo} Global $^{6}$, ganha renovado interesse diante do processo de intensificação da sociedade mundial, principalmente porque o contexto de globalização que se desenvolve na atualidade atinge os mais diversos campos da atividade humana.

Entendendo-se que o Constitucionalismo Global, numa aproximação conceitual provisória, consiste na perspectiva que se refere à aplicação de princípios tipicamente constitucionais na esfera jurídica internacional/global, este artigo tem por objetivo identificar algumas das tendências e das concepções teóricas que possam contribuir para uma melhor compreensão do fenômeno em estudo, escolhidas dentre outras, justamente por servirem de modelos alternativos, cada qual com as suas particularidades, nessa era caracterizada pela ótica "pósnacional" ou das "constelações pós-nacionais".

Algumas percepções podem justificar a abordagem, tais como as tendências desintegradoras do modelo de soberania estatal, a importância de novos atores adnata à proliferação de fontes normativas e de instâncias decisórias no cenário internacional, a confusão entre os limites externos e internos, bem como a existência de normas jurídicas internacionais, com efeito erga omnes e jus cogens.

Os argumentos a seguir explorados, embora de maneira sintética, têm um caráter metodológico preliminar para permitir, ao final, examinar-se indutivamente a pertinência e as possibilidades de estudo que o tema comporta para o enfrentamento de uma nova ordem mundial, cuja feição começa a se descortinar, na qual os paradigmas característicos que se plasmaram na ideia de Estadonação parecem não mais corresponder satisfatoriamente.

$5 \quad$ VERDROSS, Alfred. Die Verfassung der Völkerrechtsgemeinschaft (The Constitution of the International Legal Community). Wien - Berlin: Springer, 1926.

6 Para fins deste artigo, entende-se que as expressões "Constitucionalismo Global" e "Constitucionalismo Internacional" são sinônimas. Todavia, prefere-se a primeira em razão da sua amplitude significativa, de forma a permitir outras possibilidades além daquelas restritas à relação entre Estados. 


\section{OS DESAFIOS DA GOVERNANÇA PARA ALÉM DA ESFERA ESTATAL}

Como resposta ao ambiente multifacetado, no qual se intensificam as relações sociais mundiais de forma a incluir, além dos Estados, outros atores, como as organizações intergovernamentais e não governamentais, as forças de mercado e os segmentos da sociedade civil, afigura-se necessária a reflexão sobre os limites e as possibilidades do aperfeiçoamento da governança tendo em vista os temas e os interesses envolvidos.

Inicialmente, cabe ressaltar que a categoria governança não se confunde com a categoria governo. A governança refere-se à existência de um processo político que "envolve a construção de consenso, ou a obtenção de consentimento ou aquiescência necessária para realizar um programa, em uma arena onde muitos diferentes interesses estão em jogo". ${ }^{7}$ Quanto à categoria governo, refere-se a instituições formais que são parte de um sistema hierárquico-normativo. $O$ Governo tem o poder tanto de tomar decisões que são vinculativas como de reforçar seus cumprimentos, ou seja, por intermédio de autoridade. ${ }^{8}$ Conforme Rosenau, se os sistemas de regras dos governos podem ser pensados como estruturas, os de governança se caracterizam como funções sociais ou processos para a execução de diversas maneiras, em diversos momentos e em diversos lugares por uma ampla variedade de organizações. ${ }^{9}$

No entanto, é perceptível a existência de uma diversidade de interesses e finalidades, que podem ser identificados, conforme Hewitt de Alcántara, nos

7 Conforme HEWITT DE ALCÁNTARA, Cynthia. Uses and Abuses of the Concept of Governance. In: Internacional Social Science Journal, v. 50, 1998, p. 105-113.

8 Para uma distinção das categorias Governo e Governança, ver também: BRÜHL, Tanja; RITTBERGER, Volker. From international to global governance: Actors, collective decisionmaking, and the United Nations in the world of the twenty-first century. In: RITTBERGER, Volker (Ed.). Global Governance and the United Nations System. United Nations University: United Nations University Press, 2001. p. 5. Numa tentativa de aperfeiçoamento conceitual, Brühl e Rittberger distinguem Governança Global de Governança Internacional: a Governança Global caracteriza-se por uma diminuição dos Estados e um acréscimo no envolvimento de atores não estatais. Enquanto que na Governança Internacional os destinatários e os produtores de normas e regras são estados e outras instituições intergovernamentais, na Governança Global também são incluídos os atores não estatais (p. 2).

9 ROSENAU, James N. Governance in a New Global Order. In: HELD, David; McGREW, Anthony. Governing Globalization: power, authority and global governance. Cambridge (UK): Polity Press, 2002 (reprinted in 2007, 2010). p. 72. 
seguintes aspectos: a) para aqueles que desejam uma diminuição da presença marcante do Estado nas áreas econômica e social, de forma a deslocar parte da discussão da esfera governamental para o campo mais abrangente da governança; b) a utilização da expressão "boa governança" como facilitação de programas de reforma de Estado com um apelo mais técnico e menos político; c) outros, que não têm interesse na redução do papel dos governos nacionais, usam o conceito de governança para os problemas que necessitam ação conjunta em diversos níveis (do local ao supranacional), cujo Estado tem dificuldade ou não pode exercer liderança; d) fortalecimento da cultura cívica, promovendo a ação voluntária de forma a melhorar as bases sociais para a democracia; e) forma como a comunidade internacional pode construir instituições para promover a ordem e a justiça no contexto da globalização. ${ }^{10}$

Pode-se observar, conforme exemplificam Brühl e Rittberger, a dificuldade no cumprimento das metas e das finalidades de governança nos sistemas internacionais, em que os Estados desempenham fundamental papel, como na insuficiência de proteção a determinados territórios ou populações quanto à guerra e às dificuldades de Estados e do sistema internacional em lidar com a prática de crimes que ultrapassam fronteiras (tráfico de drogas, terrorismo por organizações transnacionais, etc.) e de problemas ambientais. Ademais, em muitos Estados não é garantida a segurança jurídica. Essas dificuldades do sistema internacional em atingir as metas suficientes de governança podem ser percebidas também nas questões que envolvem a participação dos cidadãos nas decisões políticas, bem como no defict socioeconômico referente a desigualdades entre ricos e pobres. Podem também ser constatadas lacunas ou falhas jurisdicionais, operacionais, de incentivo e de participação, que contribuem para uma redução na legitimidade dos sistemas de governança internacional. ${ }^{11}$

Peters, identificando resquícios de direito constitucional em diversos níveis de governança (como especificamente os direitos humanos e o comércio), visualiza a

10 HEWITT DE ALCÁNTARA, Cynthia. Uses and Abuses of the Concept of Governance. In: Internacional Social Science Journal, v. 50, 2008, p. 105-113.

11 Conforme BRÜHL, Tanja; RITTBERGER, Volker. From international to global governance: Actors, collective decision-making, and the United Nations in the world of the twenty-first century. In: RITTBERGER, Volker (Ed.). Global Governance and the United Nations System. United Nations University: United Nations University Press, 2001. p. 2 Especificamente sobre a diminuição da legitimidade nos sistemas de governança, p. 21-24. 
existência de uma rede constitucional, relacionada à interação entre normas e seus destinatários. Os elementos fragmentários de direitos constitucional nos níveis de governança podem ser observados "tanto 'horizontalmente' (setorialmente) como 'verticalmente' (que compreende tanto o nível internacional como o nacional), e nesses níveis os elementos constitucionais "poderiam complementarse e sustentar-se um no outro". Esse entrelaçamento é que Peters denomina de "constitucional network". ${ }^{12}$

Também como resposta ao problema dos sistemas que se reproduzem de forma alargada no cenário ultra estatal destaca-se a contribuição de Slaughter. Para a referida autora, diante da realidade em que se configuram a extensão e a natureza das redes governamentais existentes, tanto horizontais como verticais, vislumbra uma "nova ordem mundial", cujo conceito refere-se à atual infraestrutura mundial, ordem esta alicerçada numa complexa rede tridimensional de interações entre instituições dos Estados desagregados. ${ }^{13}$ Para Slaughter, ${ }_{1}^{14}$ em brevíssima síntese, questões como terrorismo, crime organizado, direitos humanos, meio ambiente, finanças, comércio, etc. são objeto de esforço conjunto dos governos, por meio de redes transnacionais, em razão da intensa interdependência. Se tradicionalmente a governança global resultaria da persecução dos próprios interesses nacionais

12 Conforme PETERS, Anne. Constitucionalismo compensatório: las funciones y el potencial de las normas y estructuras internacionales. In: PETERS, Anne; AZNAR, Mariano J.; GUTIÉRREZ, Ignacio. La Constitucionalización de La Comunidad Internacional. Tradução de Mariano J. Aznar Gómez e Alejandra Laura Videla. Valência: Tirant lo Blanch, 2010. p. 245. Para Peters (p. 246), "A edificação de uma rede constitucional transnacional, na qual as normas aplicáveis não podem ser alinhdas em uma hierarquia abstrata, tem ao menos uma importante consequência jurídica: a solução de eventuais conflitos entre o direito constitucional nacional e internacional requer um balanço dos interesses em casos concretos". No texto original: "La edificación de una red constitucional transnacional, en la cual las normas aplicables no pueden ser alineadas en una jerarquía abstracta, tiene al menos una importante consecuencia jurídica: la solución de eventuales conflictos enter el derecho constitucional nacional e internacional requiere un balance de los intereses de los casos concretos".

13 Slaughter conceitua "Ordem Mundial" como "um sistema de governança global que institucionaliza a cooperação e suficientemente contenha os conflitos de tal forma que as nações e seus povos possam alcançar uma maior paz e prosperidade, melhorar a gestão da terra e atingir padrões mínimos de dignidade humana". (Livre tradução). No original: "... a system of global governance that institutionalizes cooperation and sufficiently contains conflict such that all nations and their peoples may achieve greater peace and prosperity, improve their stewardship of the earth, and reach minimum standards of human dignity". In: SLAUGHTER, Anne-Marie. A New World Order. Princeton: Princeton University Press, 2004. p. 15.

14 SLAUGHTER, Anne-Marie. A New World Order. Princeton: Princeton University Press, 2004. 
pelos Estados, para Slaughter essa governança operacionalizaria-se de forma descentralizada por juízes, reguladores e legisladores, bem como por intermédio de organizações não governamentais que atuam em temas específicos. Um dos aspectos abordados diz respeito às interações entre juízes e tribunais nacionais, regionais e internacionais num complexo processo de globalização da jurisprudência ("transjudicialismo").

$\mathrm{Na}$ avaliação desse promissor contexto, mesmo que diversas dificuldades possam ser apontadas, principalmente quanto à transparência e à legitimidade, não impedem, mas servem de estímulo para o aperfeiçoamento necessário para as organizações e para as redes de governança que refogem aos limites estatais. Pensa-se, diante disso, que os aspectos inerentes às características da esfera constitucional podem contribuir nesse sentido.

\section{O CONSTITUCIONALISMO COMPENSATÓRIO EM FACE DO FENÔMENO DA GLOBALIZAÇÃO}

Conforme já expressado no introito deste artigo, o processo de intensificação e de interdependência da sociedade mundial serve de motivo para renovar o interesse no debate sobre o Constitucionalismo Global. Essa sensação também é percebida por Dunoff e Trachtman quando admitem que a globalização poderia influenciar ou contribuir com a constitucionalização do direito internacional. ${ }^{15}$

De fato, pode-se constatar um relacionamento comum e de reforço mútuo de certos tipos de direitos na esfera internacional. Dessa maneira, a globalização possibilita acordos de cooperação, além de permitir interações internacionais, legais e institucionais, como no comércio internacional, no combate à criminalidade organizada, na gestão ambiental, etc. Ou seja, a necessidade de normas jurídicas internacionais originaria a demanda por normas internacionais constitucionais.

Para Peters, a antiga ideia de uma Constituição para a Comunidade Jurídica Internacional, já pensada mais propriamente desde Verdross, merece de 15 DUNOFF, Jeffrey L.; TRACHTMAN, Joel P. A Functional Approach to Global Constitucionalism. In: DUNOFF, Jeffrey L.; TRACHTMANN, Joel P. (edit). Ruling the World: Constitutionalism, International Law, and Global Governance. New York: Cambridge University Press, 2009. p. 5. 
fato ser reavaliada em face da crescente interdependência decorrente de problemas globais e deslocalizados, bem como pelo desenvolvimento de redes globais nas áreas da economia, da ciência, da política e do direito. Em decorrência, na análise de Peters, os Estados são destinados a processos de cooperação não só em relação a organizações internacionais, mas também em razão de tratados bilaterais e multilaterais. Ademais, migram para outros níveis as funções exercidas tradicionalmente pelas instâncias estatais/ governamentais como a segurança, a liberdade e a igualdade e, por outro lado, atores não estatais atuam nos Estados, bem como transnacionalmente para lidar com temas antes circunscritos às fronteiras domésticas, inclusive nas áreas militar e policial, tão ligadas ao ente estatal. ${ }^{16}$ Esse conjunto de fatores ocasiona um processo de governança para além dos limites estatais para lidar com temas de interesse público.

Diante disso, entende que as constituições estatais não mais dão conta de regular suficientemente a governança, afetando desde o princípio democrático até o próprio direito e a segurança das pessoas. Em consequência dessa "desconstitucionalização", Peters propõe "buscar uma constitucionalização compensatória no plano internacional" para que, de forma abrangente em diversos níveis de governança, possa ocorrer uma efetivação constitucional completa. ${ }^{17}$ Ante o esvaziamento e a disfunção no campo das constituições estatais, o constitucionalismo compensatório no plano internacional teria por escopo a preservação dos princípios do constitucionalismo. ${ }^{18}$

16 Conforme PETERS, Anne. Compensatory Constitutionalism: The Function and Potential of Fundamental Norms and Structures. In: Leiden Journal of International Law. N. 19, 2006. p. 579-610. Texto também publicado em: PETERS, Anne. Constitucionalismo compensatório: las funciones y el potencial de las normas y estructuras internacionales. In: PETERS, Anne; AZNAR, Mariano J.; GUTIÉRREZ, Ignacio. La Constitucionalización de La Comunidad Internacional. Tradução de Mariano J. Aznar Gómez e Alejandra Laura Videla. Valência: Tirant lo Blanch, 2010. p. 207-261.

17 PETERS, Anne. Compensatory Constitutionalism: The Function and Potential of Fundamental Norms and Structures. In: Leiden Journal of International Law. N. 19, 2006. p. 580.

18 PETERS, Anne [2009d]. The Merits of Global Constitutionalism. Indiana Journal of Global Legal Studies. Vol. 16 (Summer 2009). p. 405. 


\section{O PROJETO DO DIREITO ADMINISTRATIVO GLOBAL}

No âmbito da presente abordagem, também importa mencionar o projeto do Direito Administrativo Global (Global Administrative Law - GAL), criado pelo esforço conjunto de juristas como Sabino Cassese, Nico Krisch, Benedict Kingsburry, Richard B. Stewart, e outros, que surge como resposta à propagação e à expansão dos sistemas regulatórios globais, que se multiplicam nas diversas áreas e se desenvolvem no ambiente ultraestatal, ou seja, escapam ao controle do Estado e são reguladas em nível global, como a pesca, o meio ambiente (ex: Organização Meteorológica Mundial, organismos encarregados da aplicação da Convenção das Nações Unidas sobre as Mudanças Climáticas e do Programa sobre o Meio Ambiente das Nações Unidas), o domínio marinho (a Organização Marítima Internacional, a Autoridade Internacional dos Fundos Marinhos, o Tribunal Internacional do Direito do Mar), a navegação aérea e marítima, a agricultura, os alimentos, os serviços postais, as telecomunicações, Internet (a ICANN - Internet Corporation for Assigned Names and Numbers), a propriedade intelectual, as fontes de energia, o domínio econômico e financeiro (ex. Fundo Monetário Internacional, Banco Mundial), etc. ${ }^{19}$

A propósito, convém estabelecer uma conceituação de Direito Administrativo Global como:

(...) aquele que compreende os mecanismos, princípios, práticas e apoiar os acordos sociais que os assegurem e que promovam ou que de outra forma afetem a accountability dos órgãos administrativos globais, em particular, garantindo o cumprimento dos standards adequados de transparência, participação, tomada de decisões fundamentadas, e legalidade, e promovendo a efetiva revisão das normas e das decisões que tomem. Os órgãos administrativos globais incluem órgãos reguladores intergovernamentais formais, redes regulatórias informais intergovernamentais e acordos de coordenação, entidades reguladoras nacionais que operam com referência a um regime internacional intergovernamental, órgãos reguladores híbridos público-privados e alguns órgãos reguladores privados que exerçam

19 CASSESE, Sabino. Global Administrative Law: an introduction. 22/2/2005. Cassese prefere a expressão "sistema regulatório global" (global regulatory system) a frequentemente utilizada expressão governança global" (global governance). 
funções de governança transnacional de especial relevância pública. ${ }^{20}$

A conformação de seu conceito inclui essa disciplina nascente no âmbito da administração regulatória e, portanto, com o caráter de Direito Administrativo, com o objeto da transparência, participação, review e accountability na governança global, nos seguintes principais âmbitos de regulação administrativa global: Administração Internacional (International Administration), por organizações internacionais; Administração em Rede (Network Administration), baseada em ação coletiva por redes transnacionais de acordos de cooperação por reguladores nacionais (como o Basel Committee of National Bank Regulators); Administração Distribuída (Distributed Administration) conduzida por reguladores nacionais sob tratados, redes, ou outros regimes cooperativos (como a Basel Convention on Transboundary movement of Hazardous Wastes); Administração Híbrida (Hybrid Administration), em arranjos entre privados e intergovernamentais, como a ICANN - Internet Corporation for Assigned Names and Numbers; e a Administração Privada (Private Administration), ou seja, instituições privadas que possuem funções regulatórias, como no caso da ISO (International Organization for Standartization). ${ }^{21}$

Para Krisch, existe uma significativa repercussão no Direito Internacional pelo fato de que o poder público cada vez mais é levado para o nível de governança global, de forma que os princípios políticos e jurídicos dos Estados também são transferidos para o âmbito global. Defende o pluralismo existente no Direito Administrativo Global como alternativa à constitucionalização da ordem política global numa estruturação unitária e coerente, pois esta última tende a minimizar a diversificação da política mundial. ${ }^{22}$

20 Livre tradução: No original: "... as comprising the mechanisms, principles, practices, and supporting social understandings that promote or otherwise affect the accountability of global administrative bodies, in particular by ensuring they meet adequate standards of transparency, participation, reasoned decision, and legality, and by providing effective review of the rules and decisions they make. Global administrative bodies include formal intergovernmental regulatory bodies, informal intergovernmental regulatory networks and coordination arrangements, national regulatory bodies operating with reference to an international intergovernmental regime, hybrid public-private regulatory bodies, and some private regulatory bodies exercising transnational governance functions of particular public significance". In: KINGSBURY, Benedict; KRISCH, Nico; STEWART, Richard. The Emergence of Global Administrative Law. International Law and Justice Working Papers 2004/1 (Law and Contemporary Problems), vol. 68, 2005. p. 17.

21 Extraído do sítio do Institute for International Law and Justice (New York University School of Law). In: <http://www.iilj.org/GAL/GALworkingdefinition.asp>.

$22 \mathrm{KRISCH}$, Nico. The Pluralism of Global Administrative Law. The European Journal of In- 
Ao examinar o problema da proximidade do Direito Administrativo Global e do Constitucionalismo Global, Ming-Suo Kuo entende que ambas constituem o que se pode denominar de "public law", cuja relação assim é expressada:

Minha investigação sobre a relação entre direito administrativo e direito constitucional global sugere unidade da legalidade global, seja chamado de direito administrativo ou constitucionalismo global . Defendo que esta unidade identitária entre direito administrativo e direito constitucional no contexto global consistem em dupla reflexividade, enquanto um exame mais estreito essa unidade reflexiva é a fragmentação ou separação entre direito administrativo global e constitucionalismo, colocando desafios para o ideal da "rule of law" global". Por um lado, os administrativistas globais focam na coordenação geral ou racionalização de políticas administrativas, sem prestar atenção suficiente aos seus Impactos no desenvolvimento de um constitucionalismo global. Por outro lado, como premissa do constitucionalismo global sobre as práticas de regulação global, os constitucionalistas globais esquecem os problemas inerentes ao direito administrativo global. Como resultado, o status quo do direito administrativo global somente pode se sustentar "terceirizando" os desafios fundamentais para o constitucionalismo global. Em suma, a legalidade global é salva de fragmentação não por um direito público global unitário, mas assumindo a "dualidade jurídica" que estamos acostumados no pensamento jurídico tradicional. ${ }^{23}$

De fato, podem ser percebidas certas aproximações entre o Constitucionalismo Global e o Direito Administrativo. Se no aspecto conceitual o Direito Administrativo Global apresenta-se, prima facie, como um debate distinto, Schwöbel, entretanto,

ternational Law, v.17, 2006. p. 247-248.

23 Livre tradução. No texto original: My investigation of the relationship between global administrative law and global constitutional law suggests the unity of global legality, whether it be called administrative law or constitutionalism. I argue that this identitarian unity between administrative law and constitutional law in the global context consist of dual reflexivity, while on close inspection underneath this reflexive unity is the fragmentation or separation between global administrative law and global constitutionalism, posing challenges to the ideal of the global rule of law. On the one hand, global administrative lawyers focus on the global coordination or rationalization of administrative policies without paying sufficient attention to its impacts on the developement of global constitutionalism. On the other hand, by premising global constitutionalism on the practices of global regulation, global constitutionalists overlook the problems inherent in global administrative law itself. As a result, the status quo of global administrative law can hold up only by "outsourcing" the fundamental challenges to global constitutionalism. In sum, global legality is saved from fragmentation not by a unitary global public law but instead by assuming the "legal duality" we have been accustomed to in traditional legal thinking. Conforme KUO, Ming-Sung. Between Fragmentation and Unity: the Uneasy Relationship Between Global Administrative Law and Global Constitutionalism. San Diego International Law Journal, v.10, 2009, p. 467. 
vê origem comum com o Constitucionalismo Global, "eis que enraizados em pensamentos semelhantes sobre mudanças no Direito Internacional e na esfera internacional em geral". ${ }^{24}$

\section{CONSTITUCIONALIZAÇÃO SEM ESTADO: AS CONSTITUIÇÕES CIVIS COMO RESPOSTA À GLOBALIZAÇÃO POLICÊNTRICA}

Também é de grande relevância referencial, como alternativa sistêmicoteórica às abordagens tradicionais vinculadas ao direito estatal ou constitucional, a contribuição de Teubner a partir de uma "Constitucionalização sem Estado", a respeito de um ordenamento jurídico mundial além das ordens políticas nacional e internacional, cujos candidatos a esse direito mundial sem Estado seriam, inicialmente, ordenamentos jurídicos de empresas multinacionais, direito do trabalho, área de padronização técnica e do autocontrole profissional, direitos humanos, proteção ambiental e inclusive o mundo esportivo (as "constituições civis" da sociedade mundial). ${ }^{25}$ Decorre tal perspectiva de um policentrismo ocasionado pela globalização, envolvendo vários setores (político, econômico, ambiental, tecnológico, etc.) em que se articulam diversos subsistemas autônomos com a esfera internacional relacionados com outros subsistemas parciais globais.

Esse direito global, que abrange os atores privados ou quase públicos no âmbito global, permite três considerações: 1) somente pode ser exposto adequadamente por uma teoria do pluralismojurídico; 2) (como não internacional) é um ordenamento jurídico que não pode ser mensurado conforme os critérios de aferição dos sistemas jurídicos nacionais; 3) sua relativa distância das políticas internacionais não protegerá o direito mundial de uma repolitização. Contudo,

24 SCHWÖBEL, Christine E. ] [2011a]. Global Constitutionalism in International Legal

Perspective. Leiden/Boston: Martinus Nijhoff Publishers, 2011. p. 29.

25 A propósito da concepção do Societal Constitutionalism, ver: TEUBNER, Gunther. Global bukowina: legal pluralism in the World Society. (Appeared in: Gunther Teubner (ed.), Global Law Without a State. Dartmouth, Aldershot 1997, 3-28). TEUBNER, Gunther. A Bukowina Global: sobre a emergência de um pluralismo jurídico transnacional. In: Impulso: Revista de Ciências Sociais e Humanas, vol. 14, n. 33. Piracicaba: Unimep, jan./abr. 2003, p. 9-31. TEUBNER, Gunther. Societal Constitutionalism: Alternatives to State-Centred Constitutional Theory? In: Transnational Governance and Constitutionalism (Christian Joerges, Inger, Johanne Sand \& Gunther Teubner eds., 2004). TEUBNER, Gunther. Globale Zivilverfassungen: Alternativen zur staatszentrierten Verfassungstheorie (Global Civil Constitutions: Alternatives to a State-Centred Constitutional Theory), 63 ZAÖRV 3, 6 (2003). 
essa repolitização não seria realizada pelas instituições políticas tradicionais, mas por variados processos por meio dos quais o direito mundial se acopla estruturalmente com discursos altamente especializados. Para Teubner, o direito mundial se desenvolveria não a partir dos centros políticos dos Estados-nação e das instituições internacionais, mas a partir das periferias sociais. ${ }^{26}$

Teubner assevera que a proposta da constitucionalização sem Estado não é abstrata e normativa destinada a um tempo futuro, mas sim possui "a existência de uma tendência real que hoje é suscetível de ser observada". Sua tese é assim explicitada:

A constituição da sociedade mundial não se faz realidade exclusivamente nas instituições representantes da política internacional, tampouco pode acontecer em uma constituição global que abarque todos os âmbitos sociais, senão que gera, por incremento, na constitucionalização de uma multiplicidade de subsistemas autônomos da sociedade mundial. ${ }^{27}$

Para justificar a mudança de perspectiva de constituições únicas nacionais para a diversificação das Constituições civis da sociedade mundial, Teubner estabelece três circunstâncias: a primeira diz respeito ao dilema da racionalização, com base nas ideias desenvolvidas na obra Theory of Societal Constitutionalism, de David Sciulli, ${ }^{28}$ em que este estabelece quatro impulsos que se opõem a uma tendência evolutiva massiva: 1) a fragmentação das lógicas de ação, com as consequências de diferenciação exacerbada, pluralização e fechamento recíproco de esferas de sentido separadas. 2) o caráter dominante do cálculo instrumental; 3) a substituição global da coordenação informal por organização burocrática; 4) o progressivo encerramento nas "estruturas de submissão ao futuro" (carcasas de servidumbre del futuro), fora da política, diante do aumento da organização formal, cujas consequências vinculam os indivíduos a regras. ${ }^{29}$

26 TEUBNER, Gunther. Global bukowina: legal pluralism in the World Society. (Appeared in: Gunther Teubner (ed.), Global Law Without a State. Dartmouth, Aldershot 1997, 3-28).

27 Livre tradução. No original: "La constitución de la sociedad mundial no se hace realidad exclusivamente en las instituciones representantes de la política internacional, tampoco puede acontecer en uma constitución global que abarque todos los âmbitos sociales, sino que se genera, por incremento, en la constitucionalización de uma multiplicidad de subsistemas autónomos de la sociedad mundial". TEUBNER, Gunther. EI Derecho como Sistema Autopoiético de la Sociedad Global. Tradução de Manuel Cancio Meliá e Carlos Gómez-Jara Díez. Lima (Peru): ARA Editores, 2005. p. 78.

28 SCIULLI, David. Theory of Societal Constitutionalism. Cambridge: Cambridge University Press, 1992.

29 TEUBNER, Gunther. El Derecho como Sistema Autopoiético de la Sociedad Global. 
A segunda circunstância refere-se à globalização policêntrica, no âmbito de uma multiplicidade de global villages autônomas, cada uma com uma dinâmica própria. Nesse sentido, "a globalização não significa simplesmente capitalismo global, senão a realização em escala mundial da diferenciação funcional". ${ }^{30} \mathrm{O}$ terceiro diagnóstico circunstancial é denominado por Teubner de "Creeping Constitutionalism". Considerando que a política internacional não pode abarcar uma constitucionalização de todo o conjunto da sociedade mundial, bem como diante da necessidade normativa de espaços autônomos para a reflexão, Teubner entende que é possível se indagar a respeito do potencial de autoconstituição dos setores sociais globais. Diante disso, destaca a importância da juridificação e da constitucionalização entendendo que "todo processo de juridificação contém necessária e simultaneamente normas constitucionais latentes". ${ }^{31}$ De tal maneira, "a atualização da latência de elementos constitucionais comportaria a possibilidade de levar a cabo uma reflexão normativa dos processos fáticos de constitucionalização e influir em sua direção". ${ }^{32}$

Mais especificamente, Teubner escolhe questionar como a teoria constitucional inserida na tradição nacional-estatal poderia lidar com os novos desafios que se esboçam com três grandes tendências contemporâneas: a esfera digital, a privatização e a gênese de redes globais. ${ }^{33}$

Diante da constatação que não é aplicável às "constituições civis globais" a dicotomia público/privado, Teubner entende que o Direito Internacional Público

Tradução de Manuel Cancio Meliá e Carlos Gómez-Jara Díez. Lima (Peru): ARA Editores, 2005. p. 81-86.

30 TEUBNER, Gunther. El Derecho como Sistema Autopoiético de la Sociedad Global. Tradução de Manuel Cancio Meliá e Carlos Gómez-Jara Díez. Lima (Peru): ARA Editores, 2005. p. 89.

31 Livre tradução. No original: "Todo proceso de juridificación contiene necesariamente simultáneamente normas constitucionales latentes". TEUBNER, Gunther. EI Derecho como Sistema Autopoiético de la Sociedad Global. Tradução de Manuel Cancio Meliá e Carlos Gómez-Jara Díez. Lima (Peru): ARA Editores, 2005. p. 89-90.

32 Livre tradução. No original: "La actualización de la latência de elementos constitucionales comportaria la posibilidad de llevar a cabo uma reflexión normativa de los procesos fácticos de constitucionalización e influir em su direccion". TEUBNER, Gunther. EI Derecho como Sistema Autopoiético de la Sociedad Global. Tradução de Manuel Cancio Meliá e Carlos Gómez-Jara Díez. Lima (Peru): ARA Editores, 2005. p. 94.

33 TEUBNER, Gunther. El Derecho como Sistema Autopoiético de la Sociedad Global. Tradução de Manuel Cancio Meliá e Carlos Gómez-Jara Díez. Lima (Peru): ARA Editores, 2005. p. 73. 
e o Direito Privado transnacional deveriam cooperar na "análise constitucional de regimes globais". A teoria dos sistemas ofereceria três critérios: a sociedade mundial somente pode ser constitucionalizada de forma fragmentária, em "constituições de âmbitos sociais setoriais"; num sistema jurídico global não seria unitário, mas fragmentado; não se deveria contar com uma integração das constituições civis parciais por uma constituição política de conjunto, "mas se pode afirmar que na colisão de diversas constituições parciais se originam conexões em rede das constituições". ${ }^{34}$

Essa concepção das constituições civis observa alguns requisitos, como relacionados por Canotilho: são limitadas a específicos subsistemas sociais, razão pela qual não aspiram ao qualificativo de constituição mundial; aperfeiçoa-se como constituições civis fora da esfera política, e portanto com autonomia das constituições parciais globais; são constituições que são dotadas de instrumento para a produção jurídica para sua regulação, além de fundamentarem suas normas com legitimidade superior. ${ }^{35}$

Entretanto, entende-se que a concepção das "Constituições civis" globais, que subestima a presença estatal, pode ser controvertida justamente porque dispensa a essencialidade do papel dos Estados no desenvolvimento do Constitucionalismo Global.

\section{A PROPOSTA DO TRANSCONSTITUCIONALISMO COMO RACIONALIDADE TRANSVERSAL E ENTRELAÇAMENTO DE ORDENS NORMATIVAS DIVERSAS}

Noutra vertente, mas que se assemelha ao Constitucionalismo Societal no que diz respeito ao problema da globalização policêntrica decorrente da intensificação

34 TEUBNER, Gunther. El Derecho como Sistema Autopoiético de la Sociedad Global. Tradução de Manuel Cancio Meliá e Carlos Gómez-Jara Díez. Lima (Peru): ARA Editores, 2005. p. 110-111.

35 CANOTILHO, J.J. Gomes. "Brancosos" e Interconstitucionalidade: itinerários dos discursos sobre a historicidade constitucional. 2. ed. Coimbra: Almedina, 2008. p. 296. O autor também desenvolve uma crítica a essa concepção de constituições civis globais fora da política (p. 298-300). 
da sociedade mundial e dos respectivos reflexos quanto à criação e à aplicação normativa pelos diversos atores que não se limitam ao âmbito estatal, Marcelo Neves propõe e desenvolve o conceito de Transconstitucionalismo, a respeito do qual, de forma descritiva, apresentam-se a seguir alguns pontos para uma aproximação do tema.

No ambiente globalizado e multifacetado convivem os ordenamentos jurídicos nacionais e os diversos outros ordenamentos, de tal forma que nos remetem a refletir sobre as relações e os reflexos que se originam nesse cenário. Crítico $^{36}$ quanto às concepções de constitucionalismo internacional, transnacional, supranacional, estatal ou local, Marcelo Neves introduz o conceito de Transconstitucionalismo. Como fundamento de sua argumentação, parte do conceito de "razão transversal" de Wolfgang Welsch ${ }^{37}$, mas se afasta "para analisar os limites e possibilidades da existência de racionalidades transversais parciais ("pontes de transição") tanto entre o sistema jurídico e outros sistemas sociais (Constituições transversais) quanto entre ordens jurídicas no interior do direito como sistema funcional da sociedade mundial". ${ }^{38}$

Como pressuposto teórico, Neves propõe a superação do conceito de acoplamento estrutural entre sistemas funcionais da sociedade moderna de Niklas Luhmann. ${ }^{39}$ Para tanto, utiliza o conceito de racionalidade transversal

36 Para Neves, "Os modelos de constitucionalismo internacional, supranacional ou transnacional, como alternativas à fragilidade do constitucionalismo estatal para enfrentar os graves problemas da sociedade mundial, levam a perspectivas parciais e unilaterais, não oferecendo, quando considerados isoladamente, soluções adequadas para os problemas constitucionais do presente". In: NEVES, Marcelo. Transconstitucionalismo. São Paulo: Martins Fontes, 2009. p. 131.

37 Para uma aproximação quanto ao conceito de "razão transversal": WELSCH, Wolfgang. Rationality and Reason Today. In: GORDON, Dane R; NIZNIK, Józef. Criticism and Defense of Racionality in Contemporary Philosophy. Netherland/Georgia(GA): Rodopi, 1998. p.17 e seguintes. Para uma visão mais ampliada: WELSCH, Wolfgang. Vernunft. Die zeitgenössische Vernunftkritik und das Konzept der transversalen Vernunft. Frankfurt am Main: Suhrkamp 1995, stw 1996.

38 NEVES, Marcelo. Transconstitucionalismo. São Paulo: Martins Fontes, 2009. p. xxii.

39 Conforme Neves, "Os acoplamentos estruturais constituem fundamentalmente mecanismos de interpenetrações concentradas e duradouras entre sistemas sociais". (NEVES, Marcelo. Transconstitucionalismo. São Paulo: Martins Fontes, 2009. p.37). O conceito de acoplamento estrutural deriva da obra de Humberto Maturana e Francisco Varela, na área da biologia, mas trazido por Luhmann para o campo da sociologia. Sobre o desenvolvimento conceitual de acoplamento estrutural ver: LUHMANN, Niklas. Introdução à Teoria dos Sistemas (Aulas publicadas por Javier Torres Nafarrate). Tradução de Ana Cristina Arantes Nasser. Petrópolis: Vozes, 2009. p. 128-151). 
(Welsch), que diz respeito aos entrelaçamentos que servem de aprendizados ou influências recíprocas entre esferas da sociedade com racionalidades ou experiências diversas. ${ }^{40}$

Em decorrência desses pressupostos, considera a Constituição de um Estado não só como acoplamento estrutural entre o sistema político e o sistema jurídico, conforme tratado por Niklas Luhmann, "mas também como instância da relação recíproca e duradoura de aprendizado e intercâmbio de experiências com as racionalidades particulares já processadas, respectivamente na política e no direito", e que a Constituição transversal "pressupõe que a política e o direito se vinculem construtivamente no plano reflexivo, implicando observações recíprocas de segunda ordem" ${ }^{41}$

Para se definir as questões que dizem respeito ao transconstitucionalismo, é preciso desvincular, numa abertura do Constitucionalismo e do conceito clássico de Constituição ligada territorialmente a determinado Estado, até porque "Os problemas dos direitos fundamentais ou dos direitos humanos ultrapassam fronteiras, de tal maneira que o direito constitucional estatal passou a ser uma instituição limitada para enfrentar esses problemas". ${ }^{42}$ Portanto, é nessa lógica de raciocínio que afirma que os problemas constitucionais, por surgirem em diversas ordens jurídicas, diante de sua transterritorialidade exigem soluções no entrelaçamento entre as mesmas e não como circunscritas a determinado Estado.

Ao tratar especificamente do Transconstitucionalismo entre ordens jurídicas e como estas podem tratar conjuntamente de problemas constitucionais, Neves expõe o entrelaçamento exemplificando com casos concretos. Aborda, então, o Transconstitucionalismo entre direito internacional público e direito estatal, entre direito supranacional e direito estatal, entre ordens jurídicas estatais, entre ordens jurídicas estatais e transnacionais, entre ordens jurídicas estatais e ordens locais extraestatais e entre direito supranacional e direito internacional. ${ }^{43}$

De todo modo, a concepção de Neves afasta-se da "tendência de sempre identificar a existência de uma nova Constituição quando surge uma nova ordem,

40 NEVES, Marcelo. Transconstitucionalismo. São Paulo: Martins Fontes, 2009. p. 34-50.

41 NEVES, Marcelo. Transconstitucionalismo. São Paulo: Martins Fontes, 2009. p. 62-63.

42 NEVES, Marcelo. Transconstitucionalismo. São Paulo: Martins Fontes, 2009. p. 119-120.

43 NEVES, Marcelo. Transconstitucionalismo. São Paulo: Martins Fontes, 2009. p. 115-234. 
instituição ou organização jurídica na sociedade contemporânea", mas se reveste de significativa importância de compreensão e reflexão a respeito da integração da sociedade mundial em torno dos problemas constitucionais que lhe são comuns.

\section{A CONSTITUCIONALIZAÇÃO DA UNIÃO EUROPEIA E O "CONSTITUCIONALISMO MULTINÍVEL"}

Uma das mais representativas tendências em voga é a alternativa do "Constitucionalismo Multinível" (Multilevel Constitutionalism), concepção esta cuja autoria comumente se atribui a Ingolf Pernice, para designar a experiência em curso na organização supranacional da União Europeia, cujo conceito serve para explicar a interação entre o ordenamento jurídico dos Estados-membros e o Direito da União Europeia, especialmente em razão da configuração originada dos tratados de Amsterdã e Lisboa. ${ }^{44}$

Pernice, por ocasião de uma análise referente ao Tratado de Amsterdã, já pronunciava ser irrelevante "se a Europa tem uma Constituição", eis que, sendo a União Europeia um sistema de poder compartilhado entre os níveis de governança regional(Länder), nacional e supranacional, já disporia do que denomina uma "Constituição Multinível", formada mediante a relação entre as Constituições dos Estados membros vinculados por um corpo constitucional complementar, consistente nos Tratados Europeus. ${ }^{45}$ Num artigo posterior, Pernice retoma o 44 Para uma aproximação conceitual de Multilevel Constitutionalism, ver: PERNICE, Ingolf. Multilevel Constitutionalism in the European Union. WHI - Paper 5/02. Walter HallsteinInstitut. Für Europäisches Verfassungsrecht Humbolt-Universität zu Berlin. In: www.whiberlin.de/documents/whi-paper0502.pdf. Acesso em 21/05/2013. PERNICE, Ingolf. Constitutional Law Implications for a State Participating in a Process of Regional Integration: German Constitution and "Multilevel Constitutionalism". In: RIEDEL, Eibe (Ed.). German Reports on Public Law, 1998. p. 40-65. PERNICE, Ingolf. Multilevel Constitutionalism and the Treaty of Amsterdam: European Constitution-Making Revisited. Common Market Law Review, n. 36 (1999). p. 703-759 (Kluwer Law International. Printed in the Netherlands, 1999); PERNICE, I.; MAYER, F. Mayer. De la Constitution composée de I'Europe. Revue trimestrielle de droit européen 36 (2000). p. 629 e seguintes. PERNICE, Ingolf. The Treaty of Lisbon: Multilevel Constitutionalism in Action. Columbia Journal of European Law 15 (2009). p. 349 e seguintes. CANANEA, Giacinto della. Is European Constitutionalism Really "Multilevel"? (Versão revisada de Paper apresentado na $13^{a}$ German-Italian conference of public Law, Florence, 16-17/10/2009). In: www.zaoerv. de/70_2010_2_a_283_318.pdf. Acesso em: 21/05/2013.

45 No original: "A constitution made up of the constitutions of the member states bound together by a complementary constitutional body consisting of the European Treaties (Verfassungsverbund). The European Union is a divided power system, in which each level of 
conceito, que é baseado em uma abordagem contratualista, argumentando que se trata de um sistema de poderes divididos para enfrentar os desafios da globalização na era pós-nacional, coexistindo as constituições nacionais e o desenvolvimento progressivo de uma autoridade supranacional pública. ${ }^{46}$

\section{argumento da construção conceitual de Pernice, no entanto, tem alguns} contrapontos importantes, pois depende do que se compreende como Constituição. ${ }^{47}$ Além disso, é importante a crítica desenvolvida por Cananea, o qual, não sem reconhecer o valor global dessa teoria, aduz que o conceito de Constitucionalismo Multinível, embora apto a explicar a dinâmica da integração entre o direito nacional e o direito comunitário, não é suficiente a convencer, principalmente porque é um conceito descritivo e enfatiza a estrutura constitucional europeia na dimensão horizontal. Além de apontar ambiguidade

government - regional (or Lander), national (State) and supranational (European) - reflects one of two or more possible political identities of the citizens concerned". PERNICE, Ingolf. Multilevel Constitutionalism and the Treaty of Amsterdam: European Constitution-Making Revisited. Common Market Law Review, n. 36 (1999). (Kluwer Law International. Printed in the Netherlands, 1999). p. 707.

46 Segue a noção conceitual, em tradução livre: "O Constitucionalismo Multinível" destina-se a descrever e compreender o continuado processo de criação de novas estruturas de governança para complementar e construir sobre - e ao mesmo tempo mudando - as formas existentes de auto-organização do povo ou da sociedade. É uma abordagem teórica para explicar como a União Europeia pode ser conceituada como um assunto e uma criação de seus cidadãos tanto quanto os Estados são uma questão e uma criação de seus respectivos cidadãos. Os mesmos cidadãos são a fonte de legitimidade para a autoridade pública a nível europeu, bem como - em relação ao seu respectivo Estado-Membro - a nível nacional, e estão sujeitos à autoridade exercida em ambos os níveis. A Constituição Europeia poderia, então, ser composta pelas Constituições nacionais e pelos Tratados Europeus para um sistema constitucional duplo ou multinível. Em consequência, minha opinião é de que a Europa já tem uma constituição e o problema é melhorar os Tratados existentes, para o fim de melhorar o sistema, e não fazer uma nova Constituição. No original: "Multilevel Constitutionalism" is meant to describe and understand the ongoing process of establishing new structures of government complementary to and building upon - while also changing - existing forms of self-organisation of the people or society. It is a theoretical approach to explaining how the European Union can be conceptualised as a matter and creature of its citizens as much as the Member States are a matter and creature of their respective citizens. The same citizens are the source of legitimacy for public authority at the European as well as - regarding their respective Member State - at the national level, and they are subject to the authority exercised at both levels. The European Constitution would, thus, be composed by the national constitutions and the European Treaties to a bi - or multilevel constitutional system. As a consequence, my view is that Europe has already a constitution and the issue is to improve the existing Treaties in order to improve the system, not to make a new constitution". In: PERNICE, Ingolf. Multilevel Constitutionalism in the European Union. WHI - Paper 5/02. Walter Hallstein-Institut. Für Europäisches Verfassungsrecht Humbolt-Universität zu Berlin. In: www.whi-berlin.de/documents/whi-paper0502.pdf. Acesso em: 21/05/2013. p.2.

47 KLABBERS, Jan. Setting the Scene. In: KLABBERS, Jan; PETERS, Anne; ULFSTEIN, Geir. The Constitutionalization of International Law. Oxford: Oxford University Press, 2009. p. 22. 
no que concerne com relação ao termo "multinível", também é ambíguo o ponto de vista normativo. De outro modo, entende que o conceito desenvolvido por Pernice não é convincente para aqueles que se preocupam com o problema subjacente com relação à coerência global do sistema jurídico. ${ }^{48}$

Por outro lado, abordando a discussão sobre novos modelos em substituição ao paradigma clássico do constitucionalismo ocidental e também voltado especificamente ao âmbito do processo supranacional de construção europeia, Canotilho opta por seguir, em vez de conceitos como Multilevel Constitutionalism, uma teoria da interconstitucionalidade, já tratada anteriormente por Lucas Pires $^{49}$, a qual "como o nome indica, estuda as relações interconstitucionais de concorrência, convergência, justaposição e conflitos de várias constituições e de vários poderes constituintes no mesmo espaço político". ${ }^{50}$

Não é despida de polêmica a questão quanto a possível existência de uma Constituição da União Europeia, ante os diversos e complexos problemas decorrentes de tal acepção, e é bem verdade que não há um texto constitucional estabelecido como ocorre tradicionalmente nos Estados. Contudo, é certo que todo sistema político tem uma constituição a lhe estruturar e fixar as regras, valores e objetivos comuns a serem seguidos pela sociedade.

Sob outro enfoque, Stein defende o ponto de vista do importante papel no processo de constitucionalização europeia a partir da Corte de Justiça, pela sua criação das doutrinas de efeito direto, da supremacia e da noção de legislação europeia e poderes implícitos, mesmo não havendo uma constituição no sentido formal. ${ }^{51}$

O problema parece residir quanto à identidade coletiva europeia, ou seja, existe um povo europeu? Um demos? Por outro lado, trata-se de um processo

48 CANANEA, Giacinto della. Is European Constitutionalism Really "Multilevel"? (Versão revisada de Paper apresentado na $13^{a}$ German-Italian conference of public Law, Florence, 16-17/10/2009). P. 316-317.

49 PIRES, Francisco Lucas. Introdução ao Direito Constitucional Europeu. Coimbra: Almedina, 1997.

50 CANOTILHO, J.J. Gomes. "Brancosos" e Interconstitucionalidade: itinerários dos discursos sobre a historicidade constitucional. 2. ed. Coimbra: Almedina, 2008. p. 266. A propósito de uma crítica resumida das tendências do constitucionalismo global, ver p. 259345.

51 STEIN, Eric. Lawyers, Judges, and the Making of a Transnational Constitution. American Journal of International Law, n. 75. p. 1-27, 1981. 
espontâneo, ou é imposto "de cima para baixo"? A criação jurídica de uma cidadania europeia poderia ser complementar às cidadanias nacionais? Tais críticas parecem relevantes principalmente no sentido da legitimação da constitucionalização. Por outro lado, Varella ressalta o problema quanto à necessidade de entendimento da comunidade como um povo no sentido da tradição constitucional, compartilhando valores político-jurídico, especialmente se for considerado que o modo de compreender a democracia contemporânea tem sua base no Contrato Social de Rousseau, em que cujo núcleo de origem e fim último do poder político é o povo. A análise realizada por Varella aponta como o problema crucial para a União Europeia "estaria na falta de relação entre os destinatários e os emissores do poder", seja porque as instituições supranacionais (legislativo, executivo, judiciário) são formadas por eleição indireta, seja porque a União Europeia "tem uma política voltada não apenas para si, mas para o mundo. Suas decisões econômicas, políticas e jurídicas são sentidas em outros Estados, como uma união de grandes Estados, catalisada pela ação coordenada do sistema regional". ${ }^{52}$ Num outro viés, pode-se mencionar a crítica de Avelãs Nunes, que repudia o caráter ideológico neoliberal no qual estaria inserida a eventual Constituição Europeia, de forma que enfatiza que o mercado não deve sobrepor-se à política. ${ }^{53}$

Apesar dessas objeções, é possível perceber que, mesmo em fase inicial, existe um processo que abarca, senão uma tendência, um modelo peculiar para o exame das possibilidades da constitucionalização no espaço da União Europeia. A União Europeia desenvolve-se a partir de um componente político e cultural e de elementos compartilhados regionalmente e configura-se com características únicas, razão pela qual, no entender de Peters, não lhe tornam apropriada para um constitucionalismo mundial, embora reconheça que o modelo europeu teria o condão de estimular novas análises quanto ao governo democrático num nível global. ${ }^{54}$

52 VARELLA, Marcelo Dias. Internacionalização do Direito: direito internacional, globalização e complexidade. Brasília: UniCEUB, 2013. p. 122.

53 A propósito, AVELÃS NUNES, A. J. A Constituição Europeia: a constitucionalização do neoliberalismo. Coimbra/São Paulo: Coimbra Editora/Revista dos Tribunais, 2007.

54 PETERS, Anne. Constitucionalismo compensatório: las funciones y el potencial de las normas y estructuras internacionales. In: PETERS, Anne; AZNAR, Mariano J.; GUTIÉRREZ, Ignacio. La Constitucionalización de La Comunidad Internacional. Tradução de Mariano 


\section{CONSTITUCIONALIZAÇÃO NO ÂMBITO DA ORGANIZAÇÃO \\ MUNDIAL DO COMÉRCIO - OMC}

Os tratados instituidores de organizações internacionais podem induzir a discussão sobre uma constitucionalização nesse nível. O enfoque de uma Constituição no âmbito do comércio internacional, mais propriamente instituída a partir da Organização Mundial do Comércio (OMC), é uma hipótese peculiar revestida de uma gama de posicionamentos acadêmicos longe de formarem um conjunto harmônico de entendimentos.

Kadelbach e Kleinlein identificam a partir da discussão usual alguns aspectos que podem sugerir a ideia de uma constitucionalização na mencionada organização, como quando as regras econômicas internacionais de longo prazo restringem os interesses de curto prazo tanto de particulares como de servidores governamentais. Num outro prisma, pode-se vislumbrar, pelo menos como possibilidade, resquícios de rule of law concernente a decisões geradas pelo sistema obrigatório de solução de controvérsias com caráter executório de um procedimento quase-supranacional. Quanto à hierarquia normativa, pode ser observada na prioridade interna que o tratado possui em detrimento de legislação derivada. Por outro lado, os referidos autores argumentam que determinadas disposições legislativas de organismos da OMC substituem as legislações nacionais (ex.: o Codex Alimentarius Comission). Para Kadelbach e Kleinlein, a OMC passa por um processo de juridificação, e não de constitucionalização, mas que, no entanto, "os standards pelos quais tal organização é medida mudaram, e que os critérios utilizados são tomados do Direito Constitucional". ${ }^{55}$

De todo modo, o desenvolvimento da atuação da OMC pode ocasionar deficits democráticos, de forma que as críticas nesse sentido poderiam ser compensadas mediante a integração por outras fontes, como os Direitos Humanos, razão pela qual Petersmann advoga o entendimento de que os direitos humanos devem

J. Aznar Gómez e Alejandra Laura Videla. Valência: Tirant lo Blanch, 2010. p. 235.

55 KADELBACH, Stefan; KLEINLEIN, Thomas. International Law - a Constitution for Mankind? An Attempt at a Re-appraisal with an Analysis of Constitutional Principles. Duncker \& Humblot (Publish.). German Yearbook of International Law. n. 50. Berlim: Duncker \& Humblot (Publisher), 2008. p. 19. 
ser integrados na OMC e que o órgão de Solução de Controvérsias (Panels) deve interpretar as exceções gerais e as cláusulas de salvaguarda com base em direitos humanos e, por outro lado, os tribunais nacionais deveriam aplicar as decisões da referida Organização, como fruto do direito fundamental ao livre comércio. ${ }^{56}$

Ao contrário dos estudos que enfatizam as perspectivas baseadas em aspectos institucionais (John Jackson) ${ }^{57}$, do direito (Ernst-Ulrich Petersmann) e metafísicos (Joseph Weiler) ${ }^{58}$, um artigo desenvolvido por Cass explora a ideia da constitucionalização ser realizada a partir das decisões do Órgão de Apelação da OMC que correspondam à produção de uma jurisprudência de tipo constitucional, animadas por um raciocínio de referência constitucional, como democracia, governança, desenho constitucional, justiça, afetação de responsabilização pública, etc. Este fenômeno éilustrado por quatro tendências: a incorporação de doutrina constitucional (constitutional doctrine amalgamation), a constituição de um sistema (system constitution), a incorporação de temas específicos (subject matter incorporation) e a associação a valores constitucionais (constitutional value association). ${ }^{59}$

Com destaque, Peters menciona, como um tema clássico do constitucionalismo por pretender conter o poder político para a salvaguarda da autonomia do indivíduo, a possibilidade de aplicação das regras do GATT (General Agreement on Tariffs and Trade - Acordo Geral sobre Tarifas e Comércio) numa perspectiva constitucional. A possibilidade dos participantes com interesses comerciais

56 PETERSMANN, Ernst-Ulcrich. Time for a United Nations "Global Compact" for Integrating Human Rights into the Law of Worldwide Organizations: Lessons from European Integration. In: The European Journal of International Law, n. 13, 2002, p. 621 e seguintes. Ver, também: PETERSMANN, Ernst-Ulrich. The WTO Constitution and Human Rights. Journal of International Economic Law, v.3, p. 19-25, 2000.

57 Jackson elabora sua análise sobre a constitucionalização no âmbito da OMC com ênfase no aspecto da estrutura institucional. In: JACKSON, John. The WTO "Constitution" and Proposed Reforms: Seven "Mantras" Revisited. Journal of International Economic Law. v. 4, 2001, p. 67-78.

58 Weiler entende a constitucionalização do GATT em termos estruturais. WEILER. Joseph H.H (Ed.). The EU, the WTO and the NAFTA: Towards a Common Law of International Trade? Oxford: Oxford University Press, 2000. p. 230.

59 Para Cass, os argumentos apresentados no referido artigo modificam a discussão quanto a OMC ser ou uma Constituição para o campo das especulações sobre a natureza do comércio internacional e da própria ideia de constitucionalização. In: CASS, Deborah Z. The "Constitutionalization" of International Trade Law: judicial norm-generation as the engine of constitutional development in International Trade. In: The European Journal of International Law - EJIL, v. 12. n. 1 p. 39-75, 2001. 
quanto à efetivação de regras do comércio internacional junto às cortes nacionais "fortaleceria aos indivíduos e permitiria ao poder judicial o controle dos executivos que, do contrário, gozam de uma discricionariedade sem limites na aplicação de regras que na realidade foram pensadas para controlar esses mesmos atores". ${ }^{60}$

As considerações particularizadas no âmbito da OMC parecem não permitir ainda uma conclusão satisfatória quanto ao processo de constitucionalização, mas se revestem de importância por analisarem a respeito da utilização de aspectos de cunho constitucional nessa específica organização internacional, ou seja, limitado a esse subsistema.

\section{A CARTA DAS NAÇÕES UNIDAS COMO UMA CONSTITUIÇÃO PARA A COMUNIDADE INTERNACIONAL}

Distintas escolas de pensamento, cada qual com suas particularidades, procuram sistematizar as razões e as consequências do Constitucionalismo Global, algumas delas mencionando o papel da Carta das Nações Unidas. ${ }^{61}$

A New Haven School (ou abordagem da Ciência Política), em que se sobressaem Myres McDougal e Michael Reisman, tem origem nos anos 50 do século passado, no período abrangido pela "guerra fria" e, destoando da tradição analítica com seu referencial nas regras, trata-se de escola orientada para o processo e para o contexto. No que concerne à Carta da ONU, os referidos autores entendem que resulta de uma decisão constitutiva (porque identifica tanto os decision-makers como os procedimentos para a tomada de decisões) e que, embora tida apenas como uma parte de um amplo processo constitutivo, o que adota é apenas o início de um processo contínuo de mudança constitucional na comunidade mundial. ${ }^{62}$ 60 PETERS, Anne. Constitucionalismo compensatório: las funciones y el potencial de las normas y estructuras internacionales. In: PETERS, Anne; AZNAR, Mariano J.; GUTIÉRREZ, Ignacio. La Constitucionalización de La Comunidad Internacional. Tradução de Mariano J. Aznar Gómez e Alejandra Laura Videla. Valência: Tirant lo Blanch, 2010. p. 237.

61 Para uma síntese quanto às abordagens de algumas destas escolas (ex.: a concepção inaugural de Verdross, a abordagem da New Haven School, a doutrina da Comunidade Internacional e a abordagem construtivista), ver: FASSBENDER, Bardo. The United Nations Charter as the Constitution of the International Community. Leiden (Netherlands): Martinus Nijhoff, 2009. p. 27-51.

62 A propósito: MCDOUGAL, Myres S.; REISMAN, Michael W. International Law in Policy-Ori- 
Na concepção do "construtivismo", Nicholas Onuf procura harmonizar a tradição analítica com abordagem de McDougal (New Haven School), por entender que tanto as regras como a realidade social são relevantes para o universo jurídico. ${ }^{63}$ Para Onuf, qualquer sociedade, inclusive a sociedade internacional, é entendida tanto como algo (thing) como também como um processo (process). ${ }^{64}$ Embora assevere que a sociedade internacional não tem uma constituição que seja anunciada como tal, argumenta que existem rudimentos de uma constituição no sentido material no que denomina o mais importante tratado multilateral, qual seja, a Carta das Nações Unidas. Mais especificamente, afirma que "Se a Carta contém uma constituição material, suas disposições encontram-se no Capítulo I (Artigos 1 e 2)". ${ }^{65}$ Identifica, por exemplo, que o Preâmbulo da Carta (We the peoples of the United Nations - Nós os povos das Nações Unidas) sinaliza uma regra de reconhecimento da soberania de vários dos povos, da mesma forma que o $\S 1^{\circ}$ do Artigo 2, em conjunto com o $\S 7$, oferece outra regra de reconhecimento. ${ }^{66}$ A respeito do $\$ 4^{\circ}$ do Artigo 2, Onuf vislumbra que se caracteriza como jus cogens, "uma regra imperativa do direito a qual somente pode ser substituída por outra regra também peremptória". ${ }^{67}$ Aliás, acredita que todo o Capítulo I tem essa característica peremptória, atribuindo que o mesmo se destaca do resto da Carta das Nações Unidas e também do Direito Internacional. Pela aproximação do Capítulo I da Carta de um modelo de Constituição, reforça seu status como uma Constituição material ("That Chapter I approximates a model constitution strengthens the case for its status as a material constitution").68

ented Perspective. In: The Structure and Process of International Law: Essays in Legal Philosophy. Doctrine and Theory 103 (R.St. J. Macdonald \& Douglas M. Johston eds., 1986); REISMAN, Michael W. Les vues de la New Haven School of International Law (Artigo traduzido por Nicolas Castoldi). In: L'Ecole de New Haven de Droit International. Tradução sobre a direção de Julien Cantegreil. Paris: Pedone, 2010). Para um apanhado geral sobre a New Haven School ver: FASSBENDER, Bardo. The United Nations Charter as the Constitution of the International Community. Leiden (Netherlands): Martinus Nijhoff, 2009. p. 36-41.

63 ONUF, Nicholas. The Constitution of International Society. European Journal of International Law, v.5, 1994, p. 1-19.

64 ONUF, Nicholas. The Constitution of International Society, p. 1.

65 ONUF, Nicholas. The Constitution of International Society, p. 16.

66 ONUF, Nicholas. The Constitution of International Society, p. 16.

67 No original: "a peremptory rule of law which may only be superseded by another such peremptory rule". In: ONUF, Nicholas. The Constitution of International Society, p. 16.

68 ONUF, Nicholas. The Constitution of International Society. European Journal of International Law, v.5, p. 1-19, 1994. p. 17. 
$\mathrm{Na}$ análise de Dupuy, dois pontos podem ser destacados para o exame quanto à função e à posição da Carta das Nações Unidas: no sentido substancial, a confrontação dos princípios estabelecidos na Carta e aqueles mais evidenciados entre as normas que se compreendem como jus cogens e, no sentido instrumental ou formal, cabe verificar a eficiência dos mecanismos para garantira implementação do conteúdo substancial da Carta por todos os Estados membros, especialmente em razão de aspectos práticos envolvendo a Corte Internacional de Justiça (ICJ) e o Conselho de Segurança das Nações Unidas. ${ }^{69}$ Conforme Dupuy, a importância da promoção da Carta das Nações Unidas como uma constituição da comunidade internacional representaria um ambicioso projeto de cooperação envolvendo os Estados membros. Conforme conclui o referido autor, "é ao mesmo tempo o convênio básico da comunidade internacional e a constituição mundial, já realizada e ainda por vir". ${ }^{70}$

Uma das abordagens a propósito do caráter constitucional da Carta das Nações Unidas mais evidenciadas na atualidade é aquela desenvolvida por Fassbender, ao identificar diversas características que a assemelham a uma Constituição no caráter normativo. Dentre essas características, pode-se mencionar, dentre outras: a) a própria denominação como uma Carta (Charter), ao contrário do usual termo "convênio" ou "tratado"; b) a expressão "We the People of the United Nations", que revelaria uma alusão ao poder constituinte; c) a história constitucional da comunidade internacional, que desde o ano de 1945 orbita em torno da Organização das Nações Unidas, que inclusive serve como foro privilegiado para temas globais, como os direitos humanos; d) a estruturação e o funcionamento da Organização, com dispositivos próprios de governança assemelhados às Constituições dos Estados; e) a hierarquia normativa, especialmente diante do disposto no art. 103 da Carta das Nações Unidas, o qual estabelece a primazia sobre qualquer outro acordo ou tratado ("uma ordem jurídica internacional sob

69 DUPUY, Pierre-Marie. The Constitutional Dimension of the Charter of the United Nations Revisited. BOGDANDY, Armin von; WOLFRUM, Rüdiger (Editors). Max Planck Yearbook of United Nations Law. Vol. 1, 1997. p. 3-4.

70 No original: "It is at the same time the basic convenant of the international community and the world constitution, already realized and still to come". Conforme DUPUY, Pierre-Marie. The Constitutional Dimension of the Charter of the United Nations Revisited. BOGDANDY, Armin von; WOLFRUM, Rüdiger (Editors). Max Planck Yearbook of United Nations Law. Vol. 1, 1997. p. 33. 
as Nações Unidas"); f) o caráter de universalidade, abrangendo não apenas os Estados membros. ${ }^{71}$

Tais qualidades, embora assemelhadas aos aspectos inerentes às Constituições estatais, ainda parecem se apresentar prematuras para se atribuir à Carta das Nações Unidas o papel de Constituição da comunidade internacional. De todo modo, ao que parece, essa concepção apresenta-se com dificuldades para se concretizar na atualidade, indicando, dentre outros aspectos, necessárias modificações no âmbito das Nações Unidas para a ampliação de sua legitimação, a começar pelo Conselho de Segurança.

\section{CONSIDERAÇÕES FINAIS}

Conforme anunciado no pórtico desta abordagem, este artigo destina-se a organizar um breve apanhado de algumas das tendências teóricas que procuram enfrentar os novos desafios do mundo globalizado.

Os fragmentos que compõem esse estudo meramente preliminar, notadamente diante da internacionalização do Direito e das interações domésticas com o cenário que se desenvolve para além das tradicionais fronteiras jurídicas e políticas estatais, podem apontar alguns importantes rumos por onde as investigações e as reflexões possam trilhar.

Por outro lado, podem servir de estímulo para explorar um importante campo de pesquisa que se descortina com bastante atualidade: a perspectiva do Constitucionalismo Global.

Os limites e as possibilidades de se transferir os aportes ligados ao Constitucionalismo, tais como a rule of law, a democracia, a separação dos poderes e o check and balances, a accountability, etc., para além das fronteiras do Estado pode parecer, num primeiro momento, um avanço que ainda recomenda cautela. 2009. p. 86-115. 
Pelo que se pode perceber dos fragmentos teóricos expostos, a transferência das mencionadas características, moldadas na experiência histórica no âmbito dos Estados, permitiria abordagens em dois aspectos: a constitucionalização global por intermédio de uma forma abrangente e unitária, como no caso da perspectiva da Carta das Nações Unidas como uma Constituição para a Comunidade Internacional, ou, de outro lado, pela constitucionalização da perspectiva pluralística, em uma série reunida de processos diferenciados.

De qualquer modo, essas perspectivas poderiam contribuir tanto para a elaboração de críticas para o enfrentamento dessa nova realidade global, como também para permitir alguma coerência ou relativa estabilidade, especialmente ao se considerar a natureza complexa e fragmentada do Direito Internacional, apesar das controvérsias que o tema poderia provocar.

O espectro de estudos parece ainda incipiente, mas o amadurecimento reflexivo a respeito mostra-se não só instigante, mas necessário. Contudo, há que se buscar na ampla gama de possibilidades maneiras de circunscrever as opções nos limites que não ultrapassem a essencialidade, ainda, do papel dos Estados, bem da proteção dos direitos humanos, do pluralismo, da autonomia dos indivíduos, e das categorias que se harmonizem com os mais elevados valores da humanidade.

\section{REFERÊNCIAS}

AVELÃS NUNES, A. J. A Constituição Europeia: a constitucionalização do neoliberalismo. Coimbra/São Paulo: Coimbra Editora/Revista dos Tribunais, 2007.

BRÜHL, Tanja; RITTBERGER, Volker. From international to global governance: Actors, collective decision-making, and the United Nations in the world of the twenty-first century. In: RITTBERGER, Volker (Ed.). Global Governance and the United Nations System. United Nations University: United Nations University Press, 2001.

CANANEA, Giacinto della. Is European Constitutionalism Really "Multilevel"? (Versão revisada de Paper apresentado na $13^{\text {a }}$ German-Italian conference of public Law, Florence, 1617/10/2009). In: www.zaoerv.de/70_2010_2_a_283_318.pdf. Acesso em: 21/05/2013. 
CANOTILHO, J.J. Gomes. "Brancosos" e Interconstitucionalidade: itinerários dos discursos sobre a historicidade constitucional. 2. ed. Coimbra: Almedina, 2008.

CASS, Deborah Z. The "Constitutionalization" of International Trade Law: judicial normgeneration as the engine of constitutional development in International Trade. In: The European Journal of International Law - EJIL, v. 12. n. 1 p. 39-75, 2001

CASSESE, Sabino. Global Administrative Law: an introduction. 22/2/2005.

DUNOFF, Jeffrey L.; TRACHTMAN, Joel P. A Functional Approach to Global Constitucionalism. In: DUNOFF, Jeffrey L.; TRACHTMANN, Joel P. (edit). Ruling the World: Constitutionalism, International Law, and Global Governance. New York: Cambridge University Press, 2009.

DUPUY, Pierre-Marie. The Constitutional Dimension of the Charter of the United Nations Revisited. BOGDANDY, Armin von; WOLFRUM, Rüdiger (Editors). Max Planck Yearbook of United Nations Law. Vol. 1, 1997.

FASSBENDER, Bardo. The United Nations Charter as the Constitution of the International Community. Leiden (Netherlands): Martinus Nijhoff, 2009.

HEWITT DE ALCÁNTARA, Cynthia. Uses and Abuses of the Concept of Governance. In: Internacional Social Science Journal, v. 50, 1998, p. 105-113.

JACKSON, John. The WTO "Constitution" and Proposed Reforms: Seven "Mantras" Revisited. Journal of International Economic Law. v. 4, 2001.

KADELBACH, Stefan; KLEINLEIN, Thomas. International Law - a Constitution for Mankind? An Attempt at a Re-appraisal with an Analysis of Constitutional Principles. Duncker \& Humblot (Publish.). German Yearbook of International Law. n. 50. Berlim: Duncker \& Humblot (Publisher), 2008.

KINGSBURY, Benedict; KRISCH, Nico; STEWART, Richard. The Emergence of Global Administrative Law. International Law and Justice Working Papers 2004/1 (Law and Contemporary Problems), vol. 68, 2005.

KLABBERS, Jan. Setting the Scene. In: KLABBERS, Jan; PETERS, Anne; ULFSTEIN, Geir. The Constitutionalization of International Law. Oxford: Oxford University Press, 2009.

KRISCH, Nico. The Pluralism of Global Administrative Law. The European Journal of International Law, v.17, 2006.

KUO, Ming-Sung. Between Fragmentation and Unity: the Uneasy Relationship Between Global 
Administrative Law and Global Constitutionalism. San Diego International Law Journal, v.10, p. 439-467, 2009.

LUHMANN, Niklas. Introdução à Teoria dos Sistemas (Aulas publicadas por Javier Torres Nafarrate). Tradução de Ana Cristina Arantes Nasser. Petrópolis: Vozes, 2009.

MCDOUGAL, Myres S.; REISMAN, Michael W. International Law in Policy-Oriented Perspective. In: The Structure and Process of International Law: Essays in Legal Philosophy. Doctrine and Theory 103 (R.St. J. Macdonald \& Douglas M. Johston eds., 1986).

ONUF, Nicholas. The Constitution of International Society. European Journal of International Law, v.5, 1994, p. 1-19.

NEVES, Marcelo. Transconstitucionalismo. São Paulo: Martins Fontes, 2009.

PERNICE, Ingolf. Constitutional Law Implications for a State Participating in a Process of Regional Integration: German Constitution and "Multilevel Constitutionalism". In: RIEDEL, Eibe. (Ed.). German Reports on Public Law, 1998. p. 40-65.

PERNICE, Ingolf. Multilevel Constitutionalism and the Treaty of Amsterdam: European Constitution-Making Revisited. Common Market Law Review, n. 36 (1999). p. 703-759 (Kluwer Law International. Printed in the Netherlands, 1999).

PERNICE, I.; MAYER, F. Mayer. De la Constitution composée de l'Europe. Revue trimestrielle de droit européen 36 (2000). p. 629 e seguintes.

PERNICE, Ingolf. The Treaty of Lisbon: Multilevel Constitutionalism in Action. Columbia Journal of European Law 15 (2009). p. 349 e seguintes.

PERNICE, Ingolf. Multilevel Constitutionalism in the European Union. WHI - Paper 5/02. Walter Hallstein-Institut. Für Europäisches Verfassungsrecht Humbolt-Universität zu Berlin. In: www.whi-berlin.de/documents/whi-paper0502.pdf. Acesso em 21/05/2013.

PETERS, Anne. Compensatory Constitutionalism: The Function and Potential of Fundamental Norms and Structures. In: Leiden Journal of International Law. N. 19, 2006.

PETERS, Anne. Constitucionalismo compensatório: las funciones y el potencial de las normas y estructuras internacionales. In: PETERS, Anne; AZNAR, Mariano J.; GUTIÉRREZ, Ignacio. La Constitucionalización de La Comunidad Internacional. Tradução de Mariano J. Aznar Gómez e Alejandra Laura Videla. Valência: Tirant lo Blanch, 2010.

PETERS, Anne [2009d]. The Merits of Global Constitutionalism. Indiana Journal of Global 
Legal Studies. Vol. 16 (Summer 2009).

PETERSMANN, Ernst-Ulrich. The WTO Constitution and Human Rights. Journal of International Economic Law, v.3, p. 19-25, 2000.

PETERSMANN, Ernst-Ulcrich. Time for a United Nations "Global Compact" for Integrating Human Rights into the Law of Worldwide Organizations: Lessons from European Integration. In: The European Journal of International Law, n. 13, 2002, p. 621 e seguintes.

PIRES, Francisco Lucas. Introdução ao Direito Constitucional Europeu. Coimbra: Almedina, 1997.

REISMAN, Michael W. Les vues de la New Haven School of International Law (Artigo traduzido por Nicolas Castoldi). In: L'Ecole de New Haven de Droit International. Tradução sobre a direção de Julien Cantegreil. Paris: Pedone, 2010.

ROSENAU, James N. Governance in a New Global Order. In: HELD, David; McGREW, Anthony. Governing Globalization: power, authority and global governance. Cambridge (UK): Polity Press, 2002 (reprinted in 2007, 2010).

SCHWÖBEL, Christine E. J [2011a]. Global Constitutionalism in International Legal Perspective. Leiden/Boston: Martinus Nijhoff Publishers, 2011.

SCIULLI, David. Theory of Societal Constitutionalism. Cambridge: Cambridge University Press, 1992.

SLAUGHTER, Anne-Marie. A New World Order. Princeton: Princeton University Press, 2004.

STEIN, Eric. Lawyers, Judges, and the Making of a Transnational Constitution. American Journal of International Law, n. 75. p. 1-27, 1981.

TEUBNER, Gunther. A Bukowina Global: sobre a emergência de um pluralismo jurídico transnacional. In: Impulso: Revista de Ciências Sociais e Humanas, vol. 14, n. 33. Piracicaba: Unimep, jan./abr. 2003, p. 9-31.

TEUBNER, Gunther. Societal Constitutionalism: Alternatives to State-Centred Constitutional Theory? in Transnational Governance and Constitutionalism (Christian Joerges, Inger, Johanne Sand \& Gunther Teubner eds., 2004).

TEUBNER, Gunther. Globale Zivilverfassungen: Alternativen zur staatszentrierten Verfassungstheorie (Global Civil Constitutions: Alternatives to a State-Centred Constitutional Theory), 63 ZAÖRV 3, 6 (2003). 
TEUBNER, Gunther. Global bukowina: legal pluralism in the World Society. (Appeared in: Gunther Teubner (Ed.). Global Law Without a State. Dartmouth, Aldershot 1997, 3-28).

TEUBNER, Gunther. El Derecho como Sistema Autopoiético de la Sociedad Global. Tradução de Manuel Cancio Meliá e Carlos Gómez-Jara Díez. Lima (Peru): ARA Editores, 2005.

VARELLA, Marcelo Dias. Internacionalização do Direito: direito internacional, globalização e complexidade. Brasília: UniCEUB, 2013.

VERDROSS, Alfred. Die Verfassung der Völkerrechtsgemeinschaft (The Constitution of the International Legal Community). Wien - Berlin: Springer, 1926.

VIVIANI, Maury Roberto. O Constitucionalismo Global no Cenário de uma Nova Ordem Mundial: uma crítica a partir de uma teoria forte em face da realidade das relações internacionais contemporâneas. Tese (Doutorado em Ciência Jurídica) - Curso de Doutorado em Ciência Jurídica, Universidade do Vale do Itajaí (Convênio de Dupla Titulação com a Universidade de Perúgia, Itália), 2014.

WEILER. Joseph H.H (Ed.). The EU, the WTO and the NAFTA: Towards a Common Law of International Trade? Oxford: Oxford University Press, 2000.

WELSCH, Wolfgang. Rationality and Reason Today. In: GORDON, Dane R; NIZNIK, Józef. Criticism and Defense of Racionality in Contemporary Philosophy. Netherland/ Georgia(GA): Rodopi, 1998. p.17 e seguintes.

WELSCH, Wolfgang. Die zeitgenössische Vernunftkritik und das Konzept der transversalen Vernunft. Frankfurt am Main: Suhrkamp 1995, stw 1996. 